\title{
The short-term effect of ultrasound and peripheral nerve stimulator- guided femoral nerve block with phenol on the outcomes of patients with traumatic spinal cord injury
}

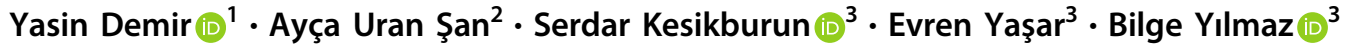

Received: 14 January 2018 / Revised: 16 March 2018 / Accepted: 26 March 2018 / Published online: 22 May 2018

(c) International Spinal Cord Society 2018

\begin{abstract}
Study design A pre-post descriptive study.

Objectives To examine the immediate effects of ultrasound-guided femoral nerve block with phenol (UGFNBwP) in managing the lower limb spasticity of individuals with traumatic spinal cord injury (SCI).

Setting Ankara, Turkey.

Methods Nineteen patients with traumatic SCI presenting with lower extremity spasticity were treated with UGFNBwP. Modified Ashworth Scale of hip flexion and knee extension, functional independence measure motor subscale, difficulty of catheterization, hygiene score, spasm frequency, sleep quality, and patient satisfaction (PS) were measured in all patients prior to treatment, in the first week and second month.

Results There was a statistically significant decrease in the Modified Ashworth Scale scores in the first week and second month compared to baseline $(p<0.017)$. Significant improvements were detected in functional independence measure motor subscale, DoC, HS, SF and PS at follow-up examinations compared to baseline $(p<0.017)$. No statistically significant difference in the SQ score was found. Patients reported no complications during the intervention and follow-up period. Conclusions Ultrasound-guided femoral nerve block with phenol is an option worth considering to reduce spasticity and improve function in people with SCI.
\end{abstract}

\section{Introduction}

More than $70 \%$ of people with spinal cord injury (SCI) have spasticity and it can have a disturbing effect on daily activities such as movement within the home, dressing, bathing, and perineal hygiene $[1,2]$. In addition, it may interfere with loss of ambulation, joint contractures, pressure ulcers, and pain [3]. Various pharmacological interventions are available to manage spasticity following SCI.

Yasin Demir

yasin.demir3@saglik.gov.tr

1 Gaziler Physical Medicine and Rehabilitation Education and Research Hospital, Ankara, Turkey

2 Karabük University Education and Research Hospital, Karabük, Turkey

3 Department of Physical Medicine and Rehabilitation, Gülhane School of Medicine, University of Health Sciences, Ankara, Turkey
The overall evidence of the efficacy of oral antispastic agents in SCI is weak and adverse drug reactions such as weakness and drowsiness are common [4]. A systematic review of the literature suggests that when all types of drugs are compared (i.e., oral, intrathecal, and/or injectable), only injectable treatments have been shown to have a positive effect on spasticity [5]. If spasticity is restricted to a few muscles, injection with botulinum toxin and chemical neurolysis with phenol might be preferred. Obturator nerve block with phenol has been shown to be effective in patients with severe hip adductor spasticity [6-12]. However, there has been only one previous study related to femoral nerve block with phenol to treat hip flexor and knee extensor muscle spasticity [6].

Poor localization of the nerve or an inadequate dose of phenol may cause treatment failure [13, 14]. In order to be close as possible to the targeted nerves, electrical stimulation has been used previously [6-12]. In addition to this technique, ultrasound (US) guidance may prevent vascular injury and reduce total elapsed time, as vascular structures and nerves can be visualized with US [15]. 
The hypothesis of this study was that US-guided femoral nerve block with phenol (UGFNBwP) can reduce spasticity. Thus, there might be improvements in the functional status, spasm frequency, and sleep quality and satisfaction level of individuals with SCI.

\section{Methods}

\section{Study design and patients}

The present study was designed as a pre-post study. Patients were recruited from the inpatient SCI Rehabilitation Unit of a tertiary rehabilitation center between September 2014 and August 2016. Inclusion criteria for the patients were (1) traumatic etiology, (2) SCI duration $>12$ months, (3) hip flexor and/or knee extensor muscle spasticity, (4) use of any oral medications to reduce spasticity at stable doses for at least 1 month before the first assessment, (5) agreement to continue with the same dose until the final assessment, and (6) medical clearance to participate. Patients with an established contracture of the knee/hip joint, aged over 65 years, history of surgery for knee/hip disorders and non-traumatic etiology were excluded. All participants provided written informed consent. The study was approved by the Local Ethics Committee of Gülhane Military Medical Academy. The study was retrospectively registered on the Clinical Trials Registry (ClinicalTrials.gov ID: NCT03468439).

\section{Assessment}

All study outcome data were collected by a physiatrist at baseline, the end of the first week, and the end of the second month. The tonicity of hip flexors and knee extensors was assessed with the Modified Ashworth Scale (MAS), which is used to describe the degree of spasticity. Changes in the functional ability of patients were tracked with the functional independence measure (FIM). Higher scores represent a greater level of independence. Items are totaled in a cognitive subscale, motor subscale, and overall FIM total score. In the current study, the motor subscale was used for functional assessment. Difficulty of catheterization was evaluated using a 5-point scale (1: very hard, 2: hard, 3: neither easy nor difficult, 4: easy, 5: very easy). The assessment of hygiene was made with the 4-point 'hygiene score' ( 0 : high difficulty performance of hygiene, 1: moderate difficulty performance of hygiene, 2: low difficulty performance of hygiene, 3: easy performance of hygiene). The spasm frequency scale was used to interpret the muscle spasms. According to this scale, the daily number of spasms were categorized as 'no spasms', 'one spasm per day', ' 2-5 times per day', '5-9 times per day' and 'more than 10 times

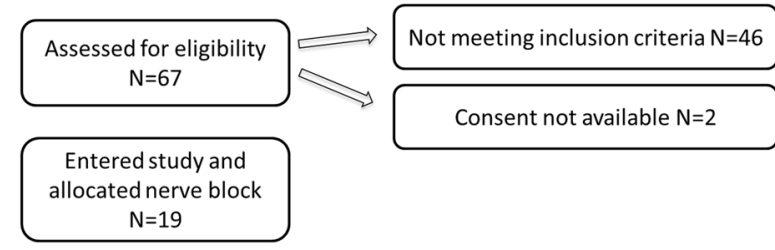

Allocation: Femoral
nerve block with
phenol
$\mathrm{N}=19$

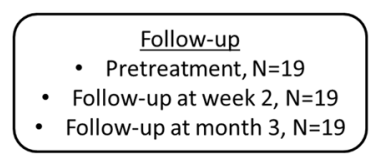

Fig. 1 Flowchart of the patients

per day' according to the frequency. Sleep quality was assessed with a 5-point Likert scale (1: very poor quality, 2: poor quality, 3: normal, 4: good quality, 5: very good quality). Patient satisfaction with the treatment was assessed on a 5-level scale ('no satisfaction,' ' slightly satisfied,' 'normal,' 'very satisfied,' and 'extremely satisfied').

\section{US-guided femoral nerve injection}

A total of 19 UGFNBwP were applied to 14 patients by another physiatrist experienced in US guidance and femoral nerve block (Fig. 1). Visualization of the femoral nerve with US was obtained with the $12-5 \mathrm{MHz}$ linear transducer (LOGIQ E Portable; GE Healthcare, China). The patient was positioned supine with the leg in a neutral position. The probe was placed in the axial position on the anterior surface of the groin. Identification of the pulsating femoral artery at the level of the inguinal crease was the initial move for orientation. If the femoral artery and the deep artery of the thigh were both seen, the transducer was moved proximal until only the femoral artery was seen. The femoral vein was visualized medial to the femoral artery. The femoral nerve was typically seen as hyperechoic and roughly triangular or oval in shape, deep to the fascia and lateral to the femoral artery (Fig. 2a). A 22 G 100-mm Teon-coated needle (Stimuplex, B. Braun) was inserted and directed parallel to the long axis of the transducer until reaching femoral nerve (Fig. 2b). The femoral nerve neurolysis was performed under peripheral nerve stimulator (Stimuplex S, B. Braun, Melsungen, Germany) guidance as well as US guidance. The frequency of stimulation was 1 $\mathrm{Hz}$ for $0.1 \mathrm{~ms}$ and the initial intensity of stimulation was 3 $\mathrm{mA}$. Targeted nerve location was decided when the muscle twitch was seen with $0.2-0.7-\mathrm{mA}$ electrical stimulation. Then, $3 \mathrm{ml}$ of $5 \%$ phenol was administered to the perineural area. 

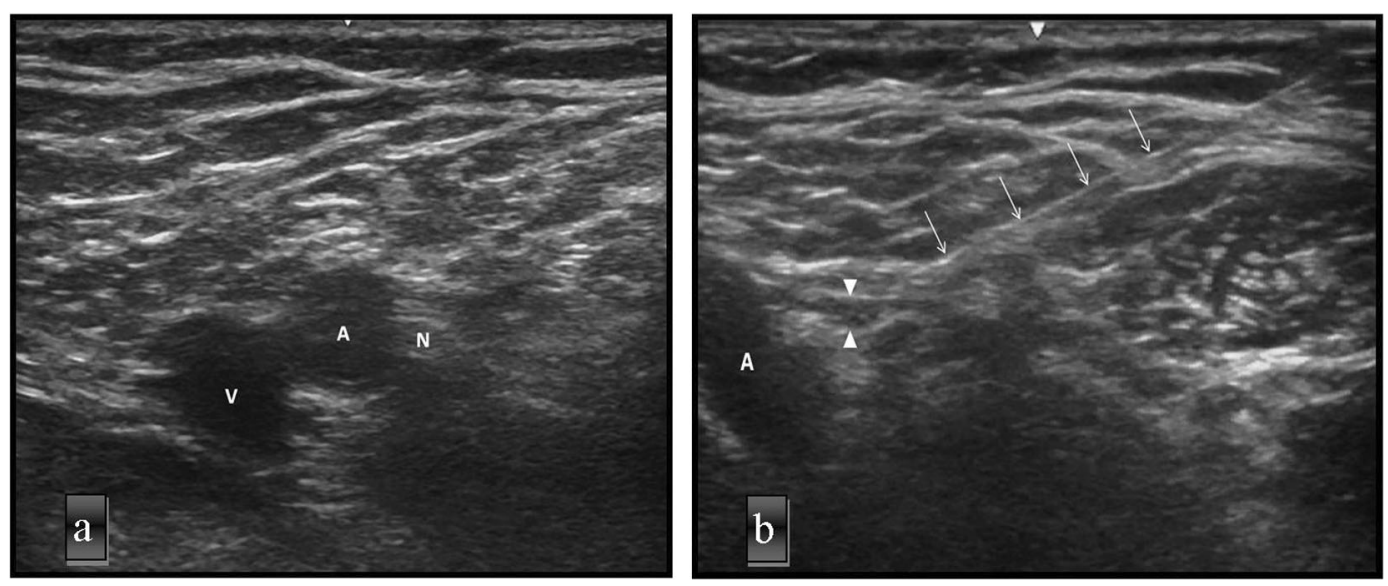

Fig. 2 a The transverse US image of the groin shows the femoral vein (V), the femoral artery (A) and the femoral nerve (N). b The needle (arrows) is advanced to the femoral nerve (arrow heads) immediately lateral to the femoral artery (A)

\section{Data analysis}

Statistical analysis was performed using SPSS v.15.0 for Windows software (SPSS, Chicago, IL, USA). Continuous variables were stated as mean \pm standard deviation (SD). Categorical variables were stated as number $(n)$ and percentage (\%). The non-parametric Friedman test was used for three repeated measurements. Binary comparisons were made using the Wilcoxon sign-rank test. A value of $p<$ 0.017 was considered statistically significant after Bonferroni adjustment.

\section{Results}

The mean age of the patients was $33 \pm 9.4$ years. The male to female ratio was 3.6/1. The mean duration from onset of SCI to phenol neurolysis was $90.7 \pm 104.5$ months. The leading etiological factor was motor vehicle accident. In total, $79 \%$ of the patients were motor complete (AIS A and B), and $21 \%$ were motor incomplete (AIS C and D). The demographic and clinical features of the patients are summarized in Table 1. Changes in MAS, FIM motor subscale, difficulty of catheterization, hygiene score, frequency of spasm, sleep quality, and satisfaction level between pretreatment and follow-up values at the end of the first week and the second month are presented in Table 2.

Significant $(p<0.017)$ decreases in the MAS scores of the hip flexor muscle tone measured at first week assessment (mean (SD), $0.7 \pm 0.8$ ) and second month follow-up assessment (mean (SD), $0.6 \pm 0.8$ ) after the UGFNBwP were found when compared to the baseline scores (mean (SD), $1.6 \pm 1.1$ ).

Spasticity in the MAS scores of the knee extensor muscle tone decreased significantly $(p<0.017)$ from baseline
Table 1 Demographic and clinical features of the patients

\begin{tabular}{ll}
\hline & Patients \\
\hline $\begin{array}{l}\text { Age (years) } \\
\text { Gender }\end{array}$ & $33 \pm 9.4$ \\
$\quad$ Male & $11(79)$ \\
$\quad$ Female & $3(21)$ \\
Time since injury (months) & $90.7 \pm 104.5$ \\
Etiology & \\
$\quad$ Motor vehicle accident & $7(50)$ \\
Fall from height & $3(21)$ \\
Diving accident & $3(21)$ \\
Crush injury & $1(7)$ \\
Level of injury & \\
Cervical & $8(57)$ \\
Thoracic & $6(43)$ \\
AIS & \\
A & $6(43)$ \\
B & $5(36)$ \\
C & $2(14)$ \\
D & $1(7)$ \\
\hline
\end{tabular}

Data are expressed as mean \pm standard deviation for continuous variables, and number (percentage) for categorical variables $A I S$ American Spinal Cord Injury Association Impairment Scale

assessment (mean (SD), $2.5 \pm 1$ ) to first week assessment (mean (SD), $0.7 \pm 1$ ) and second month follow-up assessment (mean (SD), $0.8 \pm 1$ ).

There was a statistically significant $(p<0.017)$ increase in FIM motor subtotal score from baseline (mean (SD), $32.4 \pm 21.2$ ) to first week assessment (mean (SD), $33.2 \pm$ 21.4) and then second month follow-up assessment (mean (SD), $33.2 \pm 21.4$ ). 
Table 2 Comparison of repeated outcome measures

\begin{tabular}{|c|c|c|c|c|c|c|c|c|c|}
\hline \multirow[t]{2}{*}{ Outcome measures $(\min -\max )$} & \multirow[t]{2}{*}{ Baseline } & \multirow[t]{2}{*}{$1^{\text {st }}$ week } & \multirow[t]{2}{*}{ Mean difference } & \multicolumn{2}{|c|}{$95 \% \mathrm{CI}^{1}$} & \multirow[t]{2}{*}{ 2nd month } & \multirow[t]{2}{*}{ Mean difference } & \multicolumn{2}{|c|}{$95 \% \mathrm{CI}^{2}$} \\
\hline & & & & Lower & Upper & & & Lower & Upper \\
\hline MAS-hip flexion (0-4) & $1.6 \pm 1.1$ & $0.7 \pm 0.8^{\mathrm{a}}$ & $-0.8 \pm 1$ & -1.4 & -0.3 & $0.6 \pm 0.8^{\mathrm{a}}$ & $-1 \pm 1.2$ & -1.6 & -0.4 \\
\hline MAS-knee extension (0-4) & $2.5 \pm 1$ & $0.7 \pm 1^{\mathrm{a}}$ & $-1.7 \pm 1.3$ & -2.3 & -1 & $0.8 \pm 1^{\mathrm{a}}$ & $-1.6 \pm 1.3$ & -2.3 & -1 \\
\hline FIM motor subtotal score $(0-91)$ & $32.4 \pm 21.2$ & $33.1 \pm 21.3^{\mathrm{a}}$ & $0.6 \pm 1.5$ & -0.05 & 1.4 & $33.2 \pm 21.4^{\mathrm{a}}$ & $0.7 \pm 1.5$ & 0.06 & 1.5 \\
\hline Difficulty of catheterization (1-5) & $2.6 \pm 1.2$ & $3.2 \pm 1^{\mathrm{a}}$ & $0.6 \pm 0.8$ & 0.2 & 1 & $3.4 \pm 1.1^{\mathrm{a}}$ & $0.7 \pm 0.9$ & 0.3 & 1.2 \\
\hline Hygiene score $(0-3)$ & $1.1 \pm 1$ & $2 \pm 0.7^{\mathrm{a}}$ & $0.8 \pm 0.8$ & 0.4 & 1.2 & $2.2 \pm 0.7^{\mathrm{a}}$ & $1 \pm 1.1$ & 0.4 & 1.6 \\
\hline The frequency of spasm (1-5) & $3.5 \pm 0.7$ & $3.1 \pm 0.9^{\mathrm{a}}$ & $-0.4 \pm 0.5$ & -0.6 & -0.1 & $3.3 \pm 0.8$ & $-0.2 \pm 0.6$ & -0.5 & 0.09 \\
\hline Sleep quality (1-5) & $3 \pm 1$ & $3 \pm 0.9$ & $0.5 \pm 0.4$ & -0.1 & 0.2 & $2.9 \pm 1$ & $-0.5 \pm 0.4$ & -0.2 & 0.1 \\
\hline Satisfaction level (1-5) & $3.1 \pm 0.8$ & $3.8 \pm 0.6^{\mathrm{a}}$ & $0.6 \pm 0.7$ & 0.3 & 1 & $4.4 \pm 0.5^{\mathrm{a}, \mathrm{b}}$ & $1.2 \pm 0.6$ & 0.9 & 1.5 \\
\hline
\end{tabular}

Data are expressed as mean $\pm \mathrm{SD}$

MAS Modified Ashworth scale, FIM functional independence measure, Motor FIM motor subtotal score

$\mathrm{CI}^{1}$ : Confidence interval of the difference for comparison between baseline and first week

$\mathrm{CI}^{2}$ : Confidence interval of the difference for comparison between baseline and second month

${ }^{a}$ The difference compared with the baseline was statistically significant $(p<0.017)$

${ }^{\mathrm{b}}$ The difference compared with the first week was statistically significant $(p<0.017)$

There was a statistically significant $\quad(p<0.017)$ improvement in the difficulty of catheterization value from baseline (mean (SD), 2.6 \pm 1.2 ) to first week assessment (mean (SD), $3.2 \pm 1$ ) and then second month follow-up assessment (mean (SD), 3.4 \pm 1.1 ), which meant that patients were able to perform catheterization more easily at the follow-up examinations.

The hygiene score showed a statistically significant $(p<$ 0.017 ) improvement at first week assessment (mean (SD), 2 \pm 0.7 ) and second month follow-up assessment (mean (SD), $2.2 \pm 0.7$ ) compared to baseline (mean $(\mathrm{SD}), 1.1 \pm 1$ ).

There was a statistically significant $(p<0.017)$ decrease in frequency of spasm score from baseline (mean (SD), 3.5 \pm 0.7 ) to first week assessment (mean (SD), 3.1 \pm 0.9 ). There was no significant $(p>0.017)$ difference at second month follow-up assessment (mean (SD), $3.3 \pm 0.8$ ).

The level of satisfaction increased statistically significantly $(p<0.017)$ from baseline (mean (SD), $3.1 \pm 0.8)$ to first week assessment (mean (SD), $3.8 \pm 0.6$ ) and reached a higher level at the end of the second month (mean (SD), $4.4 \pm 0.5$ ) in comparison to first month.

No statistically significant effect of UGFNBwP was observed on sleep quality during the follow-up period $(p>$ 0.017 ). The success rate in nerve location during neurolysis was $100 \%$. All patients remained stable during the blockades and no complications (dysesthesia, injection pain, muscle necrosis, skin injury, interstitial fibrosis) occurred.

\section{Discussion}

To the best of our knowledge, this is the first study to use US guidance in femoral nerve block with phenol for spasticity management of patients with SCI. The results of the study showed that UGFNBwP resulted in a significant improvement in hip flexion and knee extension spasticity. Improvements in the FIM motor subtotal score, catheterization, and hygiene score, frequency of spasm and satisfaction levels were also demonstrated. Sleep quality did not show any significant changes after UGFNBwP.

Specific nerve location with the help of US and nerve stimulation guidance allows a close approach, probably without the risk of nerve damage. Phenol must be administered as close as possible to the targeted nerve trunk due to its limited diffusion, especially when a small injection volume was selected [6]. US can be regarded as a useful support in nerve block, whether to visualize adjacent neurovascular structures or to act as a real-time guide of needle positioning relative to the nerve or related blood vessels. In addition, the use of US can enhance the success rate [16]. US can also be used for the assessment of the dissemination of the injectate. Lee and Lee [17] performed 53 US-guided multiple nerve blocks including sciatic, tibialis, ulnar, and musculocutaneous nerves with lidocaine or phenol for the management of spasticity and reported an immediate decrease in spasticity after injection. A technical success rate of $100 \%$ without any complications was also reported to have been achieved in that study. Similarly, the success rate in nerve location was $100 \%$ in the present study. Patients reported no complications during the intervention or throughout the follow-up period.

The reduction in spasticity after chemical neurolysis has been attributed to different mechanisms by various authors [18-21]. Some have argued that the mechanism of action of the phenol block is obtained by production of a chemical axonotmesis $[18,19]$. On the other hand, Dimitrijevic and 
Mathon [20] suggested that phenol reduces spasticity by partially blocking afferent stimulation entering the cord. Petrillo and Knoploch [21] showed that ankle clonus was eliminated, and resistance to passive stretch was reduced substantially after phenol neurolysis in all subjects.

There has been inconsistency regarding the effective minimal phenol dose and concentration. In previously published studies of obturator nerve block with phenol the dose has ranged from 2 to $10 \mathrm{ml}$ with concentrations of 5-6\% [6-11]. Despite variations in phenol dose and concentration, all the studies announced better outcomes. Thus, in the current study, $3 \mathrm{ml}$ of $5 \%$ phenol was preferred since it was lowest phenol dose that has been proven to be effective in blocking peripheral nerves.

Two of the most common sites of spasticity in patients with SCI are the hip and the knee. Spasticity can be associated with severe pain and become a barrier to the performance of daily living activities [22]. Furthermore, spasticity of these regions prevents patients from benefitting from an efficient therapeutic rehabilitation program. In a systematic review by Lui et al. [1], three of the four studies reported a decrease in spasticity after chemical neurolysis with phenol/alcohol. The present study revealed significant improvements in the MAS scores of the hip flexion and knee extension muscles. Decreasing hip flexion spasticity with femoral nerve block may seem complicated, but the iliacus, as part of the iliopsoas, contributes to flexion in the hip joint and is supplied with nerves by the branches of the third and second nerves of the lumbar area through the femoral nerve. Therefore, blocking the femoral nerve resulted in decreased hip flexor muscle tone in the present study.

Catheterization and hygienic care are issues that may cause considerable limitation to an individual's functionality [23]. Reduced hand dexterity and increased muscle tone have been showed to be factors associated with catheterization and perineal cleaning [22]. In the current study, significant improvements were determined in the difficulty of catheterization, hygiene score, and FIM motor subtotal scores after UGFNBwP compared to the baseline values. These better results might be explained simply by reduced muscle tone. Reducing spasticity may lead to the suppression of a significant source of strain and discomfort in performing daily perineal hygienic care and also facilitate self-catheterization of the bladder [24]. Akkaya et al. [7] and Ghai et al. [8] reported that reduced spasticity helped patients with SCI in positioning, maintaining proper perineal hygiene, and in self-care activities such as toileting and lower extremity dressing. In a study by Koyama et al. [25], femoral nerve neurolysis with phenol resulted in an improvement in standing posture, alleviation of pain, and increased walking ability.

The decision to use phenol in patients with incomplete SCI needs careful clinical consideration. Those patients may suffer from neuropathic pain, which is a long-term effect of phenol use [26]. In addition, motor and sensory function loss might be seen after phenol block. However, if spasticity in the hip flexion and knee extension muscle groups is of a level affecting ambulation or daily living activities, femoral nerve block with phenol may be an option in the treatment. Individual factors should be taken into account when deciding on the clinical management of patients with incomplete SCI.

There are a number of shortcomings related to this investigation: primarily, the lack of a control group, a low number of participants, and the assessors were not blinded. Thus, it can be recommended that further studies are conducted with a larger study with a larger sample and a longer follow-up period. Despite these limitations, the results obtained appear to be of value.

In conclusion, UGFNBwP is an option worth considering to reduce spasticity and improve function in people with SCI.

Author contributions Y.D. was responsible for writing. A.U.Ş. was responsible for acquisition of data. S.K. was responsible for analysis and interpretation of data. E.Y. was responsible for critical revision. B. Y. was responsible for study conception and design.

Conflict of interest The authors declare that they have no conflict of interest.

\section{References}

1. Lui J, Sarai M, Mills PB. Chemodenervation for treatment of limb spasticity following spinal cord injury: a systematic review. Spinal Cord. 2015;53:252-64.

2. Noreau L, Proulx P, Gagnon L, Drolet M, Laramée MT. Secondary impairments after spinal cord injury: a populationbased study. Am J Phys Med Rehabil. 2000;79:526-35.

3. Yelnik AP, Simon O, Parratte B, Gracies JM. How to clinically assess and treat muscle overactivity in spastic paresis. J Rehabil Med. 2010;42:801-7.

4. Montane E, Vallano A, Laporte JR. Oral antispastic drugs in nonprogressive neurologic diseases: a systematic review. Neurology. 2004;63:1357-63.

5. Simon O, Yelnik AP. Managing spasticity with drugs. Eur J Phys Rehabil Med. 2010;46:401-10.

6. Gündüz S, Kalyon TA, Dursun H, Möhür H, Bilgiç F. Peripheral nerve block with phenol to treat spasticity in spinal cord injured patients. Paraplegia. 1992;30:808-11.

7. Akkaya T, Unlu E, Alptekin A, Gumus HI, Umay E, Cakci A. Neurolytic phenol blockade of the obturator nerve for severe adductor spasticity. Acta Anaesthesiol Scand. 2010;54:79-85.

8. Ghai A, Sangwan SS, Hooda S, Garg N, Kundu ZS, Gupta T. Evaluation of interadductor approach in neurolytic blockade of obturator nerve in spastic patients. Saudi J Anaesth. 2013;7:420-6.

9. Wassef MR. Interadductor approach to obturator nerve blockade for spastic conditions of adductor thigh muscles. Reg Anesth. 1993;18:13-7.

10. Yaşar E, Tok F, Taşkaynatan MA, Yilmaz B, Balaban B, Alaca R. The effects of phenol neurolysis of the obturator nerve on the distribution of buttock-seat interface pressure in spinal cord injury patients with hip adductor spasticity. Spinal Cord. 2010;48:828-31. 
11. Alsuhabani A, Ethans K, Casey A, Skrabek R, Chateau D, Sutherland E. Ultrasound guided phenol block of the obturator nerve for severe adductor spasticity: a pilot study. Int J Neurorehabilitation. 2016;3:1-5.

12. Yoshida $T$, Nakamoto $T$, Kamibayashi $T$. Ultrasound-guided obturator nerve block: a focused review on anatomy and updated techniques. Biomed Res Int. 2017;2017:7023750.

13. McKinley WO, Gittler MS, Kirshblum SC, Stiens SA, Groah SL. Spinal cord injury medicine. 2. Medical complications after spinal cord injury: Identification and management. Arch Phys Med Rehabil. 2002;83:58-64.

14. Elbasiouny SM, Moroz D, Bakr MM, Mushahwar VK. Management of spasticity after spinal cord injury: current techniques and future directions. Neurorehabil Neural Repair. 2010;24: 23-33.

15. Özçakar L, Kara M, Chang KV, Çarl AB, Akkaya N, Tok F, et al. Nineteen reasons why physiatrists should do musculoskeletal ultrasound: EURO-MUSCULUS/USPRM recommendations. Am J Phys Med Rehabil. 2015;94:e45-9.

16. Peterson MK, Millar FA, Sheppard DG. Ultrasound-guided nerve blocks. Br J Anaesth. 2002;2002:621-24.

17. Lee J, Lee YS. Percutaneous chemical nerve block with ultrasoundguided intraneural injection. Eur Radiol. 2008;18:1506-12.

18. Nathan PW, Sears TA, Smith MC. Effects of phenol solutions on the nerve roots of the cat: an electrophysiological and histological study. J Neurol Sci. 1963;2:7-29.
19. Lyness WH. Pharmacology of neurolytic agents. In: Racz GB, ed.. Techniques of neurolysis. Boston: Kluwer Academic Publishers; 1989. p. $13-25$.

20. Dimitrijevic MR, Mathon PW. Studies of spasticity in man. 1. Some features of spasticity. Brain. 1967;90:1-30.

21. Petrillo CR, Knoploch S. Phenol nerve block of the tibial nerve for spasticity: a long term follow-up study. Int Disabil Stud. 1988;10:97-100.

22. Yılmaz B, Akkoç Y, Alaca R, Erhan B, Gündüz B, Yıldız N, et al. Intermittent catheterization in patients with traumatic spinal cord injury: obstacles, worries, level of satisfaction. Spinal Cord. 2014;52:826-30.

23. Pelletier CA, Ditor DS, Latimer-Cheung AE, Warburton DE, Hicks AL. Exercise equipment preferences among adults with spinal cord injury. Spinal Cord. 2014 Dec;52:874-9.

24. Viel EJ, Perennou D, Ripart J, Pélissier J, Eledjam JJ. Neurolytic blockade of the obturator nerve for intractable spasticity of adductor thigh muscles. Eur J Pain. 2002;6:97-104.

25. Koyama H, Murakami K, Suzuki T, Suzaki K. Phenol block for hip flexor muscle spasticity under ultrasonic monitoring. Arch Phys Med Rehabil. 1992;73:1040-3.

26. Lam K, Wong D, Tam CK, Wah SH, Myint MW, Yu TK, et al. Ultrasound and electrical stimulator-guided obturator nerve block with phenol in the treatment of hip adductor spasticity in longterm care patients: a randomized, triple blind, placebo controlled study. J Am Med Dir Assoc. 2015;16:238-46. 